Bartın Üniversitesi

Eğitim Fakültesi Dergisi

Cilt 5, Sayı 3, s. 718-731, Ekim 2016

BARTIN - TÜRKIYE

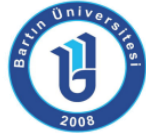

ISSN: 1308-7177
Bartin University

Journal of Faculty of Education

Volume 5, Issue 3, p. 718-731, October 2016

BARTIN - TURKEY

\title{
Revize Edilmiş İşlemsel Uzaklık Ölçeğinin Uyarlama Çalışması
}

Ramazan YILMAZ, Yrd. Doç. Dr., Bartın Üniversitesi Eğitim Fakültesi, ramazanyilmaz067@gmail.com

Yusuf Ziya OLPAK, Yrd. Doç. Dr., Ahi Evran Üniversitesi Eğitim Fakültesi, yusufziyaolpak@gmail.com

Öz: Bu araştırma kapsamında; revize edilmiş işlemsel uzaklık ölçeğinin Türk kültürüne uyarlanması ve ölçeğin geçerlilik ve güvenilirlik analizlerinin gerçekleştirilmesi amaçlanmıştır. Araştırma 227 üniversite öğrencisinden elde edilen verilerle gerçekleştirilmiştir. Üç faktörden ve 12 maddeden oluşan revize edilmiş işlemsel uzaklık ölçeği için yapılan doğrulayıcı faktör analizi sonuçları modelin gerçek verilerle uyumunun kabul edilebilir düzeylerde olduğunu göstermektedir. Güvenilirliğe ilişkin yapılan analizler ise ölçeğin güvenilir ve madde ayırt ediciliğinin yüksek olduğunu göstermiştir. Ölçeğin Türkçe formu için hesaplanan Cronbach $\alpha$ katsayıları, alt faktörler için .82 ile .93 arasında değişmekte iken, ölçeğin geneli için .89 olarak hesaplanmıştır. Bu bulgular ışığında bu araştırma kapsamında uyarlaması gerçekleştirilen revize edilmiş işlemsel uzaklık ölçeğinin, çevrimiçi öğrenme ortamlarında işlemsel uzaklık algısının belirlenmesinde kullanılabilecek geçerli ve güvenilir bir ölçme aracı olduğu söylenebilir.

Anahtar Kelimeler: İşlemsel Uzaklık, Yapı, Diyalog, Öğrenen Özerkliği

\section{The Adaptation Study of Revised Scale of Transactional Distance}

\begin{abstract}
In this research, it was aimed to adapt transactional distance scale into to educational context in Turkey. For this purpose, validity and reliability analysis were performed. The research was conducted with data obtained from 227 university students. The results of confirmatory factor analysis conducted in the process of scale adaptation of revised scale of transactional distance showed that model is coherent with real data. The analyses conducted for reliability showed that scale was reliable and item discrimination indices were high. Cronbach $\alpha$ coefficient for Turkish form was calculated for sub factors as between .82 and .93, while Cronbach $\alpha$ coefficient of whole of the scale was calculated as .89. It can be said that revised scale of transactional distance was reliable and valid data collection tool to determine perception of transactional distance in the online learning environments.
\end{abstract}

Key Words: Transactional Distance, Structure, Dialogue, Learner Autonomy 


\section{GíRiş}

Uzaktan eğitim uygulamalarının tarihsel gelişimi incelendiğinde; 20. yüzyılın büyük bölümünde mektupla öğretim ile başlayan sürecin (kâğıt, kalem ve daktilo kullanılarak öğretmen ve öğrenci arasındaki bağlantının posta servisleri ile sağlanması), radyo, televizyon, telekonferans, bilgisayar ve internet teknolojileri kullanılarak devam ettiği görülmektedir (Moore \& Anderson, 2003). Toplumsal ihtiyaç ve yapılardaki değişimler sonucu ortaya çıkan uzaktan eğitim ile ilgili olarak, alanın öncülerinden olan Moore (1993) da, uzaktan eğitimin, öğrenci ve öğretmenin basit bir coğrafik ayrılığından çok, pedagojik bir kavram olduğunu belirtmiştir. Bireylerin eğitim ihtiyaçlarının karşılanması için teknolojik olanakların gelişmesine paralel olarak, uzaktan eğitim uygulamalarının sayıları ve sağladığı olanaklar da artmış ve çeşitlenmiştir. Günümüzde daha fazla insanın, daha kolay ve ucuz bir şekilde, çok çeşitli ortamlardan yaygın bir şekilde internet teknolojilerine erişim sağlayabilmesi, eğitimde fırsat eşitsizliklerinin ortadan kaldırımasına önemli katkılar yapmakta ve uzaktan eğitim uygulamalarının da daha çok çevrimiçi olarak gerçekleştirilmesine zemin hazırlamaktadır. Brahmawong (2004) tarafından; bilgi ve tecrübenin planlanması, hazırlığı, üretimi, sunumu ve değerlendirilmesinde çekirdek ortam olarak internetin kullanıldığı ve basılı materyaller, ses kaseti, CD ve gerektiğinde yüz yüze etkileşim gibi ek ortamlarında işe koşulduğu bir uzaktan eğitim sistemi olarak tanımlanan çevrimiçi öğrenmenin de, çeşitli avantajları ve sınılılıkları bulunmaktadır. Çevrimiçi öğrenmenin; bireylere yaşam boyu öğrenme olanağı sağlaması, bireysel ve kurumsal olarak gelişim, başarı ve performansın izlenebilmesi, öğrencilerin kendi öğrenme ihtiyaç ve hızlarına bağlı olarak istenilen yer ve zamanda öğrenmeye olanak sağlaması gibi avantajları bulunmaktadır. Çevrimiçi öğrenmenin bu avantajlarının yanında; öğrencilerin öz disiplinli ve öz denetimli olmalarının gerekmesi, güdülenmişliklerinin yüksek olmasını gerektirmesi ve çalıştıkları öğrenme ortamlarında kendilerini yalnız hissetmeleri gibi sınılılıkları da bulunmaktadır (Bach, Haynes, \& Smith, 2007; de Bruyn, 2004; Drago, Peltier, \& Sorensen, 2002; Uşun, 2006). Bu bağlamda, alanyazın tarandığında, başarılı çevrimiçi öğrenme uygulamaları için etkileşime kritik bir önem yüklendiği görülmektedir (Garrison, 1991; Garrison, 2000; Holmberg, 1991; Moore \& Kearsley, 1996).

Etkileşim kavramı ile ilgili alanyazın ayrıntılı olarak incelendiğinde ise; farklı araştırmacılar tarafından önerilen farklı etkileşim türlerine rastlanılmaktadır (Anderson \& Garrison, 1998; Hillman, Willis, \& Gunawardena, 1994; Moore, 1989; Sutton, 2001). Illk olarak Moore (1989) uzaktan eğitimde öğrenci-öğretmen, öğrenci-içerik ve öğrenci-öğrenci olmak üzere üç tür etkileşim tanımlamıştır. Ardından Hillman et al., (1994) ise, Moore (1989) tarafından geliştirilen etkileşim türlerine ek olarak teknolojinin uzaktan eğitim sürecindeki artan rolünü yansıtması amacıyla öğrenci-arayüz etkileşimi adını verdikleri ve bir görevi tamamlamak için gerekli araçların kullanımı süreci olarak ifade ettikleri etkileşim türünü tanımlamışlardır. Anderson \& Garrison (1998) tarafından yapılan çalışmada ise, var olan etkileşim türlerine ek olarak öğretmen-öğretmen, öğretmen-içerik ve içerik-içerik olmak üzere üç farklı etkileşim türü daha tanımlanmıştır. Sutton (2001) ise; çevrimiçi etkileşim süreçlerinde pasif durumda olan öğrencilerin, etkin durumdaki öğrenciler arasında gerçekleşen öğrenciöğrenci ve öğrenci-öğretmen etkileşim süreçlerini gözlemlemesi ve bu gözlemlerinden öğrenmesi şeklinde gerçekleşen ve dolaylı etkileşim (vicarious interaction) olarak isimlendirilen 
etkileşim türünü tanımlamıştır. Bunların dışında da, farklı araştırmacılar değişik isimler altında etkileşim türleri tanımlamışlardır (Burnham \& Walden, 1997; Jung, Choi, Lim, \& Leem, 2002). Yapılan bu çalışmalardan da görülebileceği üzere etkileşim kavramı öğrenme ortamlarındaki anahtar rolü nedeniyle her zaman araştırmacıların dikkatini çekmiş ve üzerinde oldukça fazla çalışma yapılımıştır.

Moore (1993) tarafından yapılan çalışmada da, daha önceki bir çalışmasında tanımlanan etkileşim türleri temel alınarak (öğrenci-içerik, öğrenci-öğretmen ve öğrenciöğrenci), öğrenci ve öğretmenin çevrimiçi veya uzaktan öğrenme ortamlarında her zaman mekân olarak, bazen de hem mekân hem de zaman olarak ayrı olduğunu belirtilmiştir. Moore (1993) bu ayrılığa dayalı olarak bireylerde oluşan psikolojik ve iletişimsel boşluğu işlemsel uzaklık (transactional distance) olarak adlandırmaktadır. Bu kurama göre; işlemsel uzaklığın derecesi, öğretmen ve öğrenci arasındaki ilişkiyi; diyalog, yapı ve öğrenen özerkliği (dialogue, structure, and learner autonomy) değişkenleri ile etkilemektedir. Diyalog, bir derste öğretmenler ve öğrenciler arasındaki etkileşimlerle gelişir (Moore, 1993). Moore'a göre diyalog ve etkileşim kavramları birbirlerine çok benzerdirler ve bazen birbirlerinin yerine kullanılsalar da, aralarında önemli bir ayrım vardır. Diyalog olumlu niteliklere sahip bir etkileşimi veya etkileşimler serisini tanımlamak için kullanılır. Ancak tüm etkileşimler buna sahip olmayabilirler (Moore, 1993). Yapı ise, ders tasarımında kullanılan elemanların veya öğretim programının çeşitli iletişim araçları kullanılarak yapılandırımasıdır. Programlar yapım, kopyalama, dağıım ve kontrol gibi ihtiyaçlara göre yapılandırıırlar. Yapı, programın eğitimsel amaçları, öğretim stratejileri ve değerlendirme yöntemleri ile ilgili esneklik veya katılığı ifade eder ve tıpkı diyalog gibi nitel bir değişkendir. Örneğin; önceden kayıt edilerek bir televizyon programı aracılığı ile sunulan bir derste, her saniye neler olacağı bellidir ve öğrencilerden herhangi bir girdi alınamaması nedeniyle diyalog içermez. Bu tür bir derste öğrencilerin bireysel ihtiyaçlarına göre değişiklikler yoktur ya da çok azdır. Ancak aynı ders telekonferans yöntemi ile verilirse öğrencilerin sorularına ve yazılı gönderilerine öğretim elemanlarının yanıtlar vermelerine olanak sağlanmış olur. Böylece öğrenme ortamı daha fazla diyalog ve daha az yapı içermiş olur (Moore, 1993). Başka bir ifadeyle yapı ve diyalog ters orantılıdır. Yapı arttığında işlemsel uzaklık artar ve diyalog arttığında da işlemsel uzaklık azalır. Öğrenen özerkliği kavramı ise; öğrencilerin amaçlarına ulaşmak için, kendi yöntemlerini kullanarak, kendi kontrolleri ile öğrenme materyallerini ve programlarını kullanmaları sürecini tanımlamak için geliştirilmiştir. Diğer bir ifadeyle öğrenen özerkliğinin; öğrencilerin neyi, nasıl ve ne kadar öğreneceğine dair vermesi gereken kararlara karşılık geldiği söylenebilir (Moore, 1993).

Alanyazın incelendiğinde bireylerin işlemsel uzaklık algılarını belirleyebilmek için araştırmacıların çeşitli ölçme araçları geliştirdikleri görülmektedir (Horzum, 2011; Sandoe, 2005; Zhang, 2003). Ancak, Zhang (2003) tarafından geliştirilen işlemsel uzaklık ölçeği alanyazında geniş bir kullanım alanına sahip olmuş ve Yılmaz \& Keser (2015) tarafından Türkçe'ye de uyarlanmıştır. Zhang (2003) işlemsel uzaklık algısının birden çok bileşenden meydana geldiğini ifade ederek geliştirdiği ölçeğin alt boyutlarını; öğrenci-arayüz etkileşimi, öğrenci-ortam etkileşimi, öğrenci-öğretmen etkileşimi, öğrenci-içerik etkileşimi ve öğrenciöğrenci etkileşimi şeklinde belirlemiştir. Bununla birlikte Paul, Swart, Zhang, \& MacLeod (2015) tarafından yapılan çalışmada, 12 yıl boyunca yükseköğretimde ve özellikle uzaktan eğitimde 
meydana gelen değişimler ışığında, Zhang (2003) tarafından geliştirilen işlemsel uzaklık ölçeği incelenmiş ve günün değişen dünyasında eğitimsel araştırmalar ve öğretim uygulamaları için yapısı yeniden incelenmiştir. Paul et al., (2015) uzaktan eğitimde mobil uygulamalar ile sosyal medya gibi çeşitli araçların da kullanıldığını ifade ederek, günümüz öğrencilerinin teknoloji kullanımına yatkın olduğunu ve öğrencilerin teknolojik ortam ve arayüz kullanımı ile ilgili engellerin üstesinden gelebileceğini varsaymaktadırlar. Buna bağı olarak da araştırmacılar özellikle öğrenci-öğretmen, öğrenci-öğrenci ve öğrenci-içerik etkileşimi ile ilgili öğrencilerin işlemsel uzaklık algısını ölçmek amacıyla kullanılabilecek bir ölçme aracına ihtiyaç duyulduğunu ifade etmektedir. Paul et al., (2015) tarafından gerçekleştirilen çalışma sonucunda Zhang (2003) tarafından geliştirilen orijinal işlemsel uzaklık ölçeği; mükemmel güvenilirlik ve geçerlilik, daha iyi uyum istatistikleri, uygulanmasının daha kolay olması ve ölçeğin yanıtlanması için daha az zaman gerekmesi gibi avantajlarla üç faktörlü ve 12 maddeli olacak şekilde yeniden doğrulanmıştır. Öğrenci-öğretmen, öğrenci-öğrenci ve öğrenci-içerik arasındaki işlemsel uzaklığı belirlemeye yönelik maddeler içeren bu yeni ölçekte, orijinalinden farklı olarak öğrenci-arayüz ve öğrenci-ortam arasındaki işlemsel uzaklığa dair maddeler bulunmamakta olup, revize edilmiş işlemsel uzaklık ölçeği şeklinde isimlendirilmiştir. Bu bağlamda bu araştırmanın amacl; Zhang (2003) tarafından geliştirilen ve Paul et al., (2015) tarafından revize edilen üç faktörlü yapıya sahip olan işlemsel uzaklık ölçeğini Türk kültürüne uyarlayarak, ölçeğin geçerlilik ve güvenilirliğini incelemektir.

\section{YÖNTEM}

Bu bölümde; araştırmanın modeli, çalışma grubu, veri toplama aracı ve verilerin analizi ile ilgili bilgilere yer verilmiştir.

\subsection{Araştırmanın Modeli ve Çalışma Grubu}

Araştırma, 2015-2016 bahar döneminde Türkiye'deki bir devlet üniversitesinin çeşitli bölümlerinde öğrenimlerine devam eden ve uzaktan eğitim yolu ile ders alan 227 önlisans ve yüksek lisans öğrencisi üzerinde yürütülmüştür. Öğrencilerin 118'i (\%51.98) kadın, 109'u (\%48.02) ise erkektir.

\subsection{Veri Toplama Araçları}

Araştırma kapsamında verilerin toplanmasında; Zhang (2003) tarafından geliştirilen ve Paul et al., (2015) tarafından revize edilen işlemsel uzaklık ölçeğinin Türkçe uyarlaması ve araştırmacılar tarafından geliştirilen kişisel bilgi formu kullanılmıştır. Revize edilmiş işlemsel uzaklık ölçeğinin Türk kültürüne uyarlamasını hedefleyen bu çalışmada, öncelikle uyarlama için ölçek geliştiricilerinden gerekli izinler alınmıştır. Paul et al., (2015) tarafından 192 öğrencinin katılımı ile gerçekleştirilen çalışmada revize edilen işlemsel uzaklık ölçeği, üç faktör (öğrenciöğretmen, öğrenci-öğrenci ve öğrenci-içerik) ve 12 madde içermektedir. Ölçekteki 1. madde ters puanlanmıştır. Ölçek; "tamamen katılıyorum (5)", "katılıyorum (4)", "emin değilim (3)", "katılmıyorum (2)" ve "hiç katılmıyorum (1)" şeklinde likert tipi beşli bir derecelendirmeye sahiptir. Ölçekten elde edilen puanın yüksek olması, bireyin işlemsel uzaklık algısının düşük 
olduğunu, bir başka deyişle öğrenci-öğretmen, öğrenci-içerik, öğrenci-öğrenci etkileşimleriyle ilgili algılarının yüksek olduğunu göstermektedir.

\subsection{Verilerin Analizi}

Ölçeğin özgün faktör yapısını değiştirmeden, uzman görüşü desteği alınarak, Türk öğrencilerden oluşan katılımcılar üzerinden elde edilen puanların geçerliliğini incelemek için yapılan bu çalışmada doğrulayııı faktör analizi (DFA) kullanılmıştır. DFA, kuramsal olarak belirlenmiş bir yapının, model olarak sınandı̆ıının bir analizdir. Ayrıca, kuramsal bir yapının ya da modelin doğrulanmasında da kullanılmaktadır (Maruyama, 1998). Bu nedenle DFA ölçme araçlarının geliştirilmesi, düzenlenmesi ve yeniden gözden geçirilmesi çalışmalarında çok kullanışıdır (Floyd \& Widaman, 1995). İşlemsel uzaklık ölçeği önceden belirli bir kuramsal temellere dayandırıldığı ve faktör yapısı ortaya konulduğundan, söz konusu ölçeğin Türk kültüründe ne derece geçerli olduğunu sınamak için DFA kullanılmıştır.

Üç faktör ve 12 maddeden oluşan ölçekteki maddelerin ayırt ediciliklerini incelemek için; toplam puana göre üst-alt \%27'lik gruplar belirlenmiştir. Grupların madde ortalama puanları arasındaki farkların anlamlıı̆ı̆ı test etmek için, $t$-testi yapılmış ve madde-toplam korelasyonları hesaplanmıştır. Ölçeğin güvenilirliğini belirlemek için ise, ölçeğin geneli ve alt faktörleri için ayrı ayrı olmak üzere Cronbach $\alpha$ güvenirlik katsayısı hesaplanmıştır. Ayrıca ölçeğin faktör puanlarının ortalama ve standart sapma değerlerine bakılarak, Pearson Momentler Çarpım Korelasyon tekniği ile faktörler arasındaki korelasyonlar belirlenmiştir.

Bu tür çalışmalarda örneklem büyüklüğü analiz sonuçları üzerinde önemli bir etkiye sahiptir. Bu çalışma kapsamında da, 200'ün üzerinde öğrenciden (ölçekte yer alan toplam madde sayısının yaklaşık 20 katı) elde edilen verilerle çalışılmıştır. Bu bağlamda bu araştırmadaki örneklem sayısının, farklı araştırmacılar (Comrey \& Lee, 1992; Kass \& Tinsley, 1979; Nunnally; 1978) tarafından önerilen örneklem büyüklüğü şartlarını sağladığı ve yeterli olduğu söylenebilir.

\section{BULGULAR}

Bu bölümde; ölçeğin dil eşdeğerliği ile madde analizleri, güvenilirlik ve geçerlilik çalışmaları ile ilgili bilgilere yer verilmiştir.

\subsection{Dil Eşdeğerliliği}

İşlemsel uzaklık ölçeğinin Yılmaz \& Keser (2015) tarafından Türk kültürüne uyarlaması sürecinde yapılan dil eşdeğerliği çalışmasında, ölçeğin Türkçe ve özgün formlarının yüksek düzeyde, pozitif ve anlamlı bir ilişki gösterdiği belirlenmiştir [ $r=.82 ; p<.01]$. Bu bulgulara göre araştırmacılar, ölçeğin Türkçe ve özgün formlarının eşdeğer olduğunu belirtmişlerdir. Bu çalışma kapsamında da, ölçeğin maddelerinde herhangi bir değişme olmadan madde sayısının azaltılarak revize edilmiş halinin uyarlaması yapıldığından, ölçek maddeleri için yeniden dil eşdeğerliliği yapılmamıştır. 


\subsection{Madde Analizleri}

İşlemsel uzaklık algısı bakımından ölçek maddelerinin öğrencileri ne ölçüde ayırt ettiğini belirlemek için hesaplanan madde-toplam korelasyonuna ilişkin bulgular ile madde ortalama puanları bakımından alt-üst \%27'lik grupların kıyaslanmasına yönelik bağımsız t-testi bulguları Tablo 1'de verilmiştir.

Tablo 1.

İşlemsel Uzaklık Ölçeği Madde Analizi Sonuçları

\begin{tabular}{lcc}
\hline Madde No & $\begin{array}{c}\text { Düzeltilmiş Madde-Toplam } \\
\text { Korelasyonları }\end{array}$ & Alt \% 27-Üst \%27 Farkın Anlamlılık Testi \\
\hline M1 & .26 & -5.29 \\
M2 & .63 & -16.16 \\
M3 & .64 & -13.97 \\
M4 & .67 & -15.09 \\
M5 & .45 & -8.28 \\
M6 & .46 & -8.47 \\
M7 & .54 & -11.25 \\
M8 & .67 & -14.07 \\
M9 & .65 & -12.23 \\
M10 & .73 & -15.91 \\
M11 & .78 & -16.92 \\
M12 & .71 & -17.17 \\
p=.000 & & \\
\hline
\end{tabular}

Tablo 1 incelendiğinde, ölçek maddelerinin madde-toplam korelasyonlarını .26 ile .78 arasında değiştiği görülmektedir. Madde-toplam korelasyonları .30'un üstünde olduğundan, maddelerin öğrencileri iyi derecede ayırt ettiği söylenebilir (Büyüköztürk, 2007). Birinci madde her ne kadar .30'un altında olsa bile bu değere çok yakın olduğundan madde çıkartılmamıs ve analize devam edilmiştir. Ayrıca madde ortalama puanları açısından alt ve üst \%27'lik gruplar arasında anlamlı ( $p<.01)$ bir farklılaşma olduğu görülmüştür.

\subsection{Güvenilirlik Çalışmaları}

Ölçeğin güvenilirliğine Cronbach $\alpha$ güvenirlik katsayısı ile bakılmıştır. Uyarlaması yapılan ölçeğin alt faktörler için hesaplanan Cronbach $\alpha$ katsayıları, .82 ile .93 arasında değişmektedir. Cronbach $\alpha$ katsayısı ölçeğin tamamı için ise .89 olarak hesaplanmıştır. Ölçeğin daha önceden Türk kültürüne uyarlanan versiyonu (Yılmaz \& Keser, 2015) ile bu çalışma kapsamında uyarlaması yapılan revize edilmiş versiyonu için hesaplanan Cronbach $\alpha$ katsayıları Tablo 2'de verilmiştir. 
Tablo 2.

işlemsel Uzaklık Ölçeğinin Cronbach $\alpha$ Katsayıları

\begin{tabular}{lcc}
\hline & İ̧̧lemsel Uzaklık Ölçeği & \\
\hline \multirow{2}{*}{ Faktör Adı } & \multicolumn{2}{c}{ Cronbach $\alpha$ Değeri } \\
\cline { 2 - 3 } & Revize Edilen Versiyon & Uzun Versiyon \\
\hline Öğrenci-arayüz etkileşimi & - & .76 \\
Öğrenci-öğretmen etkileşimi & .82 & .87 \\
Öğrenci-içerik etkileşimi & .83 & .76 \\
Öğrenci-öğrenci etkileşimi & .93 & .95 \\
Öğrenci-ortam etkileşimi & - & .82 \\
\hline
\end{tabular}

Tablo 2 incelendiğinde, ölçeğin daha önce Türk kültürüne uyarlanan uzun versiyonu ile bu çalışma kapsamında uyarlaması yapılan revize edilmiş kısa versiyonunun Cronbach $\alpha$ iç tutarlılık katsayıları karşılaştırılıı̆ında, birbirlerine yakın değerler aldıkları görülmektedir.

Revize edilmiş işlemsel uzaklık ölçeği faktörlerine ait ortalama ve standart sapma değerleri ile faktörler arası ve faktör-toplam puanlar arası korelasyonlar ise Tablo 3'te verilmiştir.

Tablo 3.

Ölçek Faktörlerinin Ortalama ve Standart Sapma Değerleri ile Faktörler Arası Korelasyon Değerleri

\begin{tabular}{lccccc}
\hline & & & \multicolumn{3}{c}{ Korelasyonlar } \\
\cline { 5 - 6 } Faktör & $\bar{X}$ & SS & $\begin{array}{c}\text { Öğrenci- } \\
\text { öğretmen } \\
\text { etkileşimi }\end{array}$ & $\begin{array}{c}\text { Öğrenci-içerik } \\
\text { etkileşimi }\end{array}$ & $\begin{array}{c}\text { Öğrenci-öğrenci } \\
\text { etkileşimi }\end{array}$ \\
\hline Öğrenci-öğretmen etkileşimi & 15.66 & 3.88 & - & $.35^{* *}$ & $.51^{* *}$ \\
Öğrenci-içerik etkileşimi & 10.54 & 2.76 & & - & $.40^{* *}$ \\
Öğrenci-öğrenci etkileşimi & 19.10 & 4.98 & & $.66^{* *}$ & - \\
$\begin{array}{l}\text { Toplam } \\
* * p<.01\end{array}$ & 45.29 & 9.24 & $.80^{* *}$ & & $.87^{* *}$ \\
\hline
\end{tabular}

Tablo 3 incelendiğinde, ölçeğin toplamı ile faktörlere ilişkin puanlar arasındaki korelasyonların .66 ile .87; faktörler arasındaki korelasyonların ise .35 ile .51 arasında değerler aldığı anlaşılmaktadır. Ölçeğin geneline ve faktörlerine ait ortalama puanlar; toplam için 45.29 (SS=9.24), öğrenci-öğretmen etkileşimi faktörü için 15.66 (SS=3.88), öğrenci-içerik etkileşimi faktörü için 10.54 (SS=2.76) ve öğrenci-öğrenci etkileşimi faktörü için 19.10 (SS=4.98) olarak bulunmuştur. Faktörler arasındaki ikili korelasyonlar incelendiğinde, üç etkileşim boyutu arasında da orta düzeyde pozitif yönlü bir korelasyon olduğu bulunmuştur.

\subsection{Geçerlilik Çalışmaları}

Ölçeğin özgün faktör yapısının elde edilen verilerle uyumunu değerlendirmek amacıyla DFA ile uyum istatistikleri hesaplanmıştır. Öğrenci-öğretmen, öğrenci-içerik ve öğrenci-öğrenci etkileşimi şeklindeki üç faktörlü model için hesaplanan DFA sonuçları şöyledir: $\left(\chi^{2}=133.69\right.$, 
$\mathrm{df}=51, \mathrm{p}=.0000 ; \chi^{2} / \mathrm{df}=2.62, \mathrm{RMSEA}=0.085, \mathrm{RMR}=0.062, \mathrm{SRMR}=0.047, \mathrm{GFI}=.91, \mathrm{AGFI}=.86$, $\mathrm{IFI}=.97, \mathrm{CFI}=.97, \mathrm{NFI}=.96$ ve NNFI=.96). Analiz sonrasında modifikasyona yönelik seçenekler incelendiğinde, önerilerin $\chi^{2 y}$ ye büyük ölçüde katkı yapmayacağı görüldüğünden dolayı, öneriler gerçekleştirilmeden analiz tamamlanmıştır. Şekil 1'de revize edilmiş işlemsel uzaklık ölçeğine ilişkin yapısal eşitlik modeli değerleri verilmiştir.

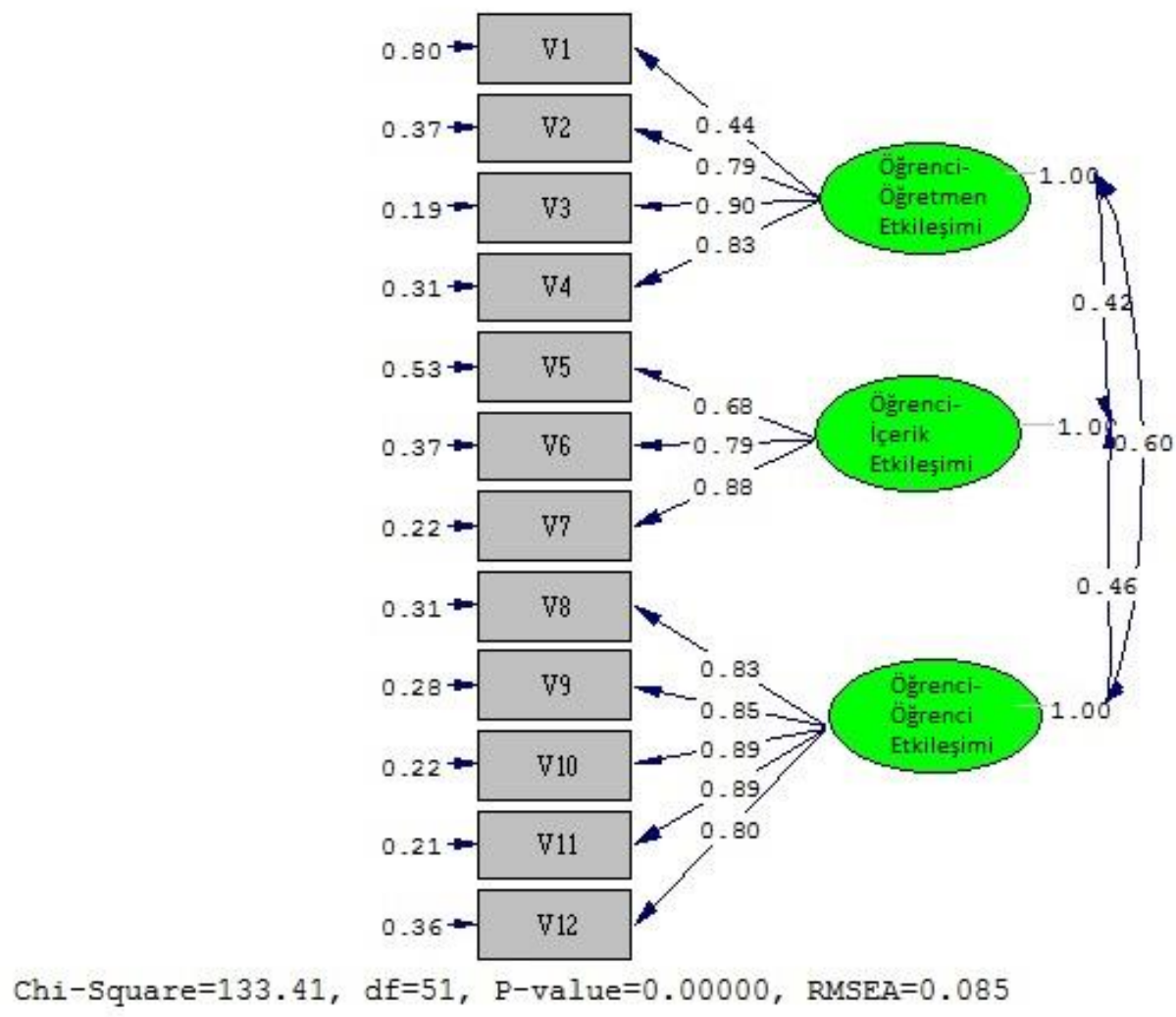

Şekil 1. Revize Edilmiş Iş̧lemsel Uzaklık Ölçeği Yapısal Eşitlik Modeli ve Standart Değerleri

DFA sonucunda $\chi^{2} / d f^{\prime}$ nin 2.62 olduğu görülmektedir. Alanyazına göre $\chi^{2} / d f^{\prime}$ nin üç veya altında olması model uyumunun kabul edilebilir olduğunu göstermektedir (Kline, 2005). RMSEA'nın .08 veya altında olması durumunda modelin iyi uyum sağladığı ifade edilmektedir (Tabachnick \& Fidell, 2007). Burada da RMSEA .085 değerini almış ve sınır değere çok yakın olduğu görülmüştür. Model incelendiğinde RMR değerinin .062 olduğu görülmüştür ve bu değerin .08'in altında olması iyi uyumun göstergesidir (Hu \& Bentler, 1999). Brown'a (2006) göre SRMR değerinin 05 veya altında olması mükemmel bir uyuma işarettir ve burada da 047 olarak bulunmuştur. GFI ve AGFI değerlerinin .90 ve üzeri olması durumunda modelin iyi uyum sağladığı ifade edilmektedir (Anderson \& Gerbing, 1984; Cole, 1987; Marsh, Balla, \& McDonald, 1988; Sümer, 2000). Bu çalışmada GFI'nın .91 değerini, AGFI'nın ise .86 değerini aldığı belirlenmiş̧ir. GFI değeri iyi uyum göstermektedir. AGFI ise her ne kadar sınır değerin altında olsa da sınıra çok yakın bir değerdedir. IFI, CFI, NFI ve NNFI değerlerinin 95 üzerinde olması durumunda modelin mükemmel uyum sağladığı ifade edilmektedir (Hu \& Bentler, 1999; Sümer, 2000). Bu çalışma kapsamında ele alınan modelde IFI .97, CFI .97, NFI .96 ve NNFI'nın 
.96 olduğu görülmektedir. Yapılan analiz için IFI, CFI, NFI ve NNFI'nın mükemmel uyum gösterdiği belirlenmiştir.

\section{TARTIŞMA, SONUÇ VE ÖNERILER}

Bu çalışmada Zhang (2003) tarafından geliştirilen işlemsel uzaklık ölçeğinin Paul et al., (2015) tarafından revize edilmiş formunun Türk kültürüne uyarlanması, geçerlilik ve güvenilirliğinin incelenmesi amaçlanmıştır. Daha önce Yılmaz \& Keser (2015) tarafından yapılan çalışmada işlemsel uzaklık ölçeğinin orijinal halinin Türk kültürüne uyarlaması sürecinde dil eşdeğerliği yapıldığından ( $r=.82 ; p<.01$ ) ve ölçeğin Paul et al., (2015) tarafından revize edilen halinde maddelerin ifade edilmesinde herhangi bir değişiklik yapılmadığından, yeniden dil eşdeğerliği yapılmamıştır. DFA sonuçları, üç faktörden oluşan revize edilmiş işlemsel uzaklık ölçeği için belirlenen modelin uyumunun kabul edilebilir düzeyde olduğunu göstermektedir. Güvenilirliğe yönelik bulgular ise ölçeğin revize formunun güvenilir olduğunu ve ölçek maddelerinin yüksek düzeyde ayırt edici olduğunu ortaya koymaktadır. Zhang (2003) tarafından geliştirilen ve Yılmaz \& Keser (2015) tarafından uyarlanan işlemsel uzaklık ölçeği; öğrenci-arayüz, öğrenci-ortam, öğrenci-öğrenci, öğrenci-içerik ve öğrenci-öğretmen etkileşimi boyutlarından oluşmaktadır. Paul et al., (2015) tarafından revize edilen işlemsel uzaklık ölçeği ise; öğrenci-öğrenci, öğrenci-içerik, öğrenci-öğretmen etkileşimi boyutlarından oluşmaktadır. Bu bağlamda çevrimiçi öğrenme ortam ve topluluklarında öğrenci-öğrenci, öğrenci-içerik ve öğrenci-öğretmen etkileşimlerine dayalı işlemsel uzaklık algısının ölçülmesinde, işlemsel uzaklık ölçeğinin revize formu kullanılabilir. Diğer taraftan, farklı etkileşim arayüz ve ortamlarının karşılaştırılmasına yönelik çalışmalarda, öğrenci-arayüz ve öğrenci-ortam etkileşimlerine yönelik tasarımsal müdahalelerin etkilerinin ölçülmesi istendiğinde ise öğrenci-arayüz ve öğrenci-ortam etkileşimlerine yönelik faktör ve maddelerin de dikkate alınması daha uygun olacaktır. Bu araştırma Türkiye'deki tek bir devlet üniversitesinde öğrenim gören ve uzaktan eğitim yolu ile dersler alan ön lisans ve yüksek lisans öğrencileri üzerinde yürütülmüştür. Bu nedenle, gelecek araştırmalarda; farklı üniversitelerdeki ve farklı eğitim düzeylerindeki öğrencilerin de dahil edildiği, daha büyük katılım oranına sahip araştırmalarla, uyarlanan revize ölçeğin geçerliliği ve güvenilirliği test edilebilir. Çevrimiçi öğrenme ortamlarının etkililiğini artırmak için; öğrencilerin çeşitli bireysel farklılıklarını dikkate alan ve öğrenci-öğrenci, öğrenciiçerik ve öğrenci-öğretmen etkileşimini sağlamaya yönelik farklı öğretim strateji, yöntem ve tekniklerinin işlemsel uzaklık algısı üzerindeki etkisinin belirlenmek istendiği çalışmalarda, ölçeğin revize formu kullanılabilir. Ayrıca, çevrimiçi öğrenme ortamlarındaki çeşitli paydaşlar (ders tasarımcıları, program yöneticileri ve öğretim elemanları gibi) tarafından, verilen eğitim değerlendirilmesinde de, uyarlanan bu ölçekten faydalanılabilir.

\section{KAYNAKLAR}

Anderson, T., \& Garrison, D. R. (1998). Learning in a networked world: New roles and responsibilities. In C. C. Gibson (Ed.), Distance Learners in Higher Education: Institutional Responses for Quality Outcomes (pp. 97-112). Atwood Publishing.

Anderson, J. C., \& Gerbing D. W. (1984). The effect of sampling error on convergence, 
improper solutions, and goodness of fit indices for maximum likelihood confirmatory factor analysis. Psychometrika, 49, 155-173.

Bach, S., Haynes, P., \& Smith, J. L. (2007). Online learning and teaching in higher education. McGraw-Hill International.

Brahmawong, C. (2004). Guidelines for internet-based distance education in colleges and universities in Thailand. International Journal of the Computer, the Internet and Management, 12(2), 7-13.

Brown, T. A. (2006). Confirmatory factor analysis for applied research. New York: Guilford Press Brown.

Burnham, B. R., \& Walden, B. (1997). Interactions in Distance Education: A report from the other side. In Annual Adult Education Research Conference Proceedings (38th, Stillwater, Oklahoma, May 16-18) (pp. 49-54).

Büyüköztürk, Ş. (2007). Sosyal bilimler için veri analizi el kitabı. Ankara: Pegem A Yayıncılık

Comrey, A. L., \& Lee, H. B. (1992). A first course in factor analysis. Hillsdale, NJ: Erlbaum.

Cole, D. A. (1987). Utility of confirmatory factor analysis in test validation research. Journal of Consulting and Clinical Psychology, 55(4), 584-594.

De Bruyn, L. L. (2004). Monitoring online communication: can the development of convergence and social presence indicate an interactive learning environment? Distance Education, 25(1), 67-81.

Drago, W., Peltier, J., \& Sorensen, D. (2002). Course content or the instructor: Which is more important in on-line teaching? Management Research News, 25(6/7), 69-83.

Floyd, F. J., \& Widaman, K. F. (1995). Factor analysis in the development and refinement of clinical assessment instruments. Psychological Assessment, 7(3), 286-299.

Garrison, D. R. (1991). Critical thinking and adult education: A conceptual model for developing critical thinking in adult learners. International Journal of Lifelong Education, 10(4), 287303.

Garrison, D. R. (2000). Theoretical challenges for distance education in the 21st century: A shift from structural to transactional issues. The International Review of Research in Open and Distance Learning, 1(1).

Hillman, D. C., Willis, D. J., \& Gunawardena, C. N. (1994). Learner-interface interaction in distance education: An extension of contemporary models and strategies for practitioners. American Journal of Distance Education, 8(2), 30-42.

Holmberg, B. (1991). The feasibility of a predictive theory of distance education: What are we allowed to expect. In B. Holmberg \& G.Ortner (Eds.), Research Into Distance Education.

Horzum, M. B. (2011). Developing transactional distance scale and examining transactional distance perception of blended learning students in terms of different variables. Educational Sciences: Theory and Practice, 11(3), 1582-1587.

Hu, L., \& Bentler, P. M. (1999). Cutoff criteria for fit indexes in covariance structure analysis: Conventional criteria versus new alternatives. Structural Equation Modeling, 6(1), 1-55.

Jung, I., Choi, S., Lim, C., \& Leem, J. (2002). Effects of different types of interaction on learning achievement, satisfaction and participation in web-based instruction. Innovations in Education and Teaching International, 39(2), 153-162. 
Kass, R. A., \& Tinsley, H. E. A. (1979). Factor analysis. Journal of Leisure Research, 11, 120-138.

Kline, R. B. (2005). Principles and practice of structural equation modeling (2nd ed.). NY: Guilford Press.

Maruyama, G. M. (1998). Basics of structural equation modeling (First Edition). CA: Sage Publications, Inc.

Marsh, H. W., Balla, J. R., \& McDonald, R. P. (1988). Goodness of fit indexes in confirmatory factor analysis: The effect of sample size. Psychological Bulletin, 103, 391-410.

Marsh, H. W., \& Hocevar, D. (1988). A new, more powerful approach to multitrait-multimethod analyses: Application of second-order confirmatory factor analysis. Journal of Applied Psychology, 73(1), 107.

Moore, M. G. (1989). Three types of interaction. American Journal of Distance Education, 3(2), $1-7$.

Moore, M. G. (1993). Theory of transactional distance. In D. Keegan (Ed.), Theoretical Principles of Distance Education (pp. 20-35). Routledge.

Moore, M. G., \& Anderson, W. G. (2003). Handbook of distance education. Routledge.

Moore, M. G., \& Kearsley, G. (1996). Distance Education: A Systems View of Online Learning, 3rd ed.: A Systems View of Online Learning. Toronto:Wadsworth.

Nunnally, J. C. (1978). Psychometric Theory (2nd ed.). New York: McGraw-Hill.

Paul, R. C., Swart, W., Zhang, A. M., \& MacLeod, K. R. (2015). Revisiting Zhang's scale of transactional distance: Refinement and validation using structural equation modeling. Distance Education, 36(3), 364-382.

Sandoe, C. (2005). Measuring transactional distance in online courses: The structure component. Unpublished Doctoral Dissertation. University of South Florida.

Sutton, L. A. (2001). The principle of vicarious interaction in computer-mediated communications. International Journal of Educational Telecommunications, 7(3), 223242.

Sümer, N. (2000). Yapısal eşitlik modelleri: Temel kavramlar ve örnek uygulamalar. Türk Psikoloji Yazıları, 3(6), 49-74.

Tabachnick, B. G., \& Fidell, L. S. (2007).Using multivariate statistics (5th ed.). New York: Allyn and Bacon

Uşun, S. (2006). Uzaktan eğitim. Nobel Yayın Dağıtım.

Yılmaz, R., \& Keser, H. (2015). İşlemsel uzaklık ölçeğinin uyarlama çalışması. Hacettepe Üniversitesi Eğitim Fakültesi Dergisi, 30(4), 91-105.

Zhang, A. (2003). Transactional distance in web-based college learning environments: Toward measurement and theory construction. Unpublished Doctoral Dissertation. Virginia Commonwealth University. 


\section{SUMMARY}

Today, the widest access to internet technologies from various environments by more people in easier and cheaper form makes important contributions to remove the inequality of opportunities in education and forms a basis for actualization of distant education implementations as online form. The online learning which is identified by Brahmawong (2004) as used in additional environments such as face-to-face interaction and printed materials, audio cassette, CD and internet which is used as core environment in evaluation, planning, preparation, production and presentation of knowledge and experience, has various advantages and restrictions. The online learning has advantages such as providing life-long education to individuals, monitoring the success and the development as corporate and individual and providing opportunity to the students to learn in needed amount and in their own learning speed from anywhere and anytime however the online learning has some restrictions such as the necessity of being self-disciplined and self-controlled and motivated and feeling themselves alone in the learning environment (Bach, Haynes, \& Smith, 2007; de Bruyn, 2004; Drago, Peltier, \& Sorensen, 2002; Uşun, 2006). In this respect, when the literature is searched, it is seen that the interaction has a critical importance for successful online learning implementations (Garrison, 1991; Garrison, 2000; Holmberg, 1991; Moore \& Kearsley, 1996).

Different interaction types which are suggested by different researchers, are seen when the literature related with interaction concept is searched in detail (Anderson \& Garrison, 1998; Hillman, Willis, \& Gunawardena, 1994; Moore, 1989; Sutton, 2001). As can be seen from these studies, the interaction concept has drawn the attention of the researches due to its key role in learning environment and many studies have been made on this concept. In the study made by Moore (1993), it is stated that the student and the teacher are always separate as location and time (student-content, student-teacher and student-student) by taking the interaction types identified in previous study as the basis and the psychological and communicative distance formed by this distance, is identified as transactional distance. According to this theory, the degree of this transactional distance affects the relationship between the student and the teacher with the variables of dialogue, structure, and learner autonomy. Dialogue develops by the interactions between the students and the teachers in a course (Moore, 1993). The structure is structuring the elements and education program used in course design by using various communication tools. The programs are structured according to needs such as manufacture, copy, distribution and control. Learner autonomy is developed for identifying the process of using the learning materials and programs with their own controls for reaching their objects. In other words, it corresponds to the decisions of the teacher related with how, what and how much to learn (Moore, 1993).

Researchers have developed different scales for determining the transactional distance perceptions of the individuals (Horzum, 2011; Sandoe, 2005; Zhang, 2003). However, the transactional distance scale which was developed by Zhang (2003) had a wide usage in the literature and was adapted into Turkish by Yllmaz \& Keser (2015). Zhang (2003) has approached to transactional distance perception as multi-dimensional and in the scale which he has developed, he has determined the sub-dimensions as student-interface interaction, 
student-content interaction, student-teacher interaction, student-student interaction and student-environment interaction. In addition, in the study made by Paul et al., (2015), under the light of the changes occurring particularly in the distant education and higher education during 12 years, the transactional distance scale developed by Zhang (2003) has been analyzed for the educational researches and education in the changing world of today. As the result of the study, the original transactional distance scale developed by Zhang (2003) has been verified as to be with 12 items and three factors with the advantages such as requiring less time for perfect reliability and validity, better fit indices. In this new scale consisting of items for determining the transactional distance between student-teacher, student-student and student-content, does not have items related with the transactional distance between student-interface and student-environment as different from its original and it is named as revised transactional distance scale. In this respect, the purpose of this research is to analyze the transactional distance scale revised by Paul et al., (2015) and developed by Zhang (2003), in terms of its reliability and validity by adapting the scale into Turkish culture.

In this research which is carried out according to research model, it is studied with the data obtained from 227 associate degree and graduate students who study through distant education and study in the various departments in a state university in Turkey at 2015-2016 spring term. 118 (51.98\%) of the students are female and 109 (48.02\%) of the are males. Turkish adaptation of the transactional distance scale developed by Zhang (2003) and revised by Paul et al., (2015) and the personal information data developed by authors are used in collection of the data. Previously, in the study made by Yilmaz \& Keser (2015), the language equalizing of the original transactional distance scale was made during the process of Turkish adaptation $(r=.82 ; p<.01)$ and no changes were made in expressing the items of scale in revised form therefore no language equalization is made. DFA results which are made during the adaptation of revised transactional distance scale consisting of three factors, showed that the harmony between the model and the actual data is in acceptable level and the analyses which were made related with the reliability showed that the scale is reliable and the item discrimination is high.

This tool can be used in the researches which analyze the effect of the different strategy, mehtod and techniques considering the various individual differences of the students on the transactional distance perceptions of the students for increasing the efficiency of the online learning environments. In addition, this scale can be used in the education evaluation given by various stakeholders (course designers, program administrators and instructors) in online learning environment. 
Ek 1. Revize Edilmiş İ̧lemsel Uzaklık Ölçeği

Faktör 1: Öğrenci-öğretmen etkileşimi

1. Öğretim elemanı bana hiç ilgi göstermiyor.

2. Öğretim elemanından akademik performansımla ilgili anında geribildirim alıyorum.

3. Öğretim elemanı bana yardımcı oldu.

4. Derste yardıma ihtiyacım olduğunda öğretim elemanından yardım alabiliyorum.

\section{Faktör 2: Öğrenci-içerik etkileşimi}

5. Bu derste; fikirleri, bilgileri veya deneyimleri yeni, daha karmaşık yorum ve ilişkilerle sentezleme ve düzenleme üzerinde durulmuştur.

6. Bu derste; başkalarının verileri nasıl topladığı ve yorumladığını incelemek gibi bilgi, argüman veya metotlar hakkında yargıda bulunma ve bunların sonuçlarının doğruluğunu değerlendirme üzerinde durulmuştur.

7. Bu derste; kavramların dayandığı kuramları, uygulamadaki sorunlara veya yeni durumlara uygulama üzerinde durulmuştur.

Faktör 3: Öğrenci-öğrenci etkileşimi

8. Sınıf arkadaşlarımla çok iyi geçiniyorum.

9. Bu çevrimiçi programdaki sınıf arkadaşlarımın bana değer verdiğini hissediyorum.

10. Bu çevrimiçi programdaki sınıf arkadaşlarım fikir ve görüşlerime çok önem veriyor.

11. Bu çevrimiçi programdaki sınıf arkadaşlarım bana saygı gösteriyor.

12. Sınıftakiler kendi kararlarımı alabilme yeteneğim konusunda destekleyiciler.

*Madde 1 ters puanlanmaktadır. 